in vivo $34: 3705-3711(2020)$

doi:10.21873/invivo.12218

\title{
A Novel Systemic Inflammatory Score Combined With Immunoinflammatory Markers Accurately Reflects Prognosis in Patients With Esophageal Cancer
}

\author{
TAKAFUMI SUZUKI, YUSUKE ISHIBASHI, HIRONORI TSUJIMOTO, SHINSUKE NOMURA, \\ KEITA KOUZU, YUJIRO ITAZAKI, TAKAO SUGIHARA, MANABU HARADA, \\ NOZOMI ITO, HIDEKAZU SUGASAWA, YOJI KISHI and HIDEKI UENO \\ Department of Surgery, National Defense Medical College, Saitama, Japan
}

\begin{abstract}
Aim: To establish a novel systemic inflammatory score (SIS) combined with neutrophil-to-lymphocyte ratio $(N L R)$, platelet-to-lymphocyte ratio (PLR), and C-reactive protein/albumin ratio $(C A R)$ and to validate its prognostic value and relation with serum cytokine levels in patients who underwent esophagectomy for esophageal cancer (EC). Patients and Methods: Preoperative NLR, PLR, and CAR were evaluated in 102 patients undergoing esophageal resection for EC from 2009 to 2014. Receiver operating characteristic (ROC) curves censored for 5-year survival were plotted to determine the cutoff values of each measure. Each measure was scored 1 if it was above the cutoff value (NLR >3.12, PLR $>230$, and $C A R>0.085$ ) and scored 0 if it was below that. The SIS was defined as the sum of these values and was divided into the two groups: High SIS (SIS=2-3) and low SIS (SIS=01). Univariate and multivariate analyses were used to determine the prognostic significance. The area under the ROCs (AUROC) was compared to verify the discriminative power of survival prediction. In addition, we analyzed the relationship between SIS and perioperative serum interleukin (IL)-6 and IL-10 levels. Results: In the clinicopathological findings, only tumor depth was significantly related to SIS $(p=0.004)$. At 0.732, the AUROC of SIS was the highest (NLR=0.618, PLR=0.545), and CAR=0.712). The high-SIS group had a significantly poorer prognosis than the low-SIS
\end{abstract}

This article is freely accessible online.

Correspondence to: Yusuke Ishibashi, MD, Department of Surgery, National Defense Medical College, 3-2 Namiki, Tokorozawa, Saitama 359-8513, Japan. Tel: +81 8032213946, Fax: +81 429965205, e-mail: yuusuke0102_0908@yahoo.co.jp

Key Words: Esophageal cancer, neutrophil-lymphocyte ratio, platelet-lymphocyte ratio, C-reactive protein/albumin ratio, prognosis. group ( $p=0.011)$. SIS was identified as an independent prognostic factor in the multivariate analysis (hazard ratio $=1.96,95 \%$ confidence intervaI $=1.11-3.41, p=0.020)$. The preoperative serum interleukin-6 level was significantly low $(p=0.046)$ and postoperative serum interleukin-10 level was significantly high in the high-SIS group $(p=0.047)$. Conclusion: SIS was a superior predictor of prognosis compared with existing immunoinflammatory markers and closely reflected the fluctuation of peripheral inflammatory cytokines in patients with EC.

Esophageal cancer (EC) is the ninth most common type of cancer and was the sixth leading cause of cancer-related deaths in 2018 (1). Even after curative surgery, the 5-year survival rate ranges from $15 \%$ to $25 \%$ in most countries due to the high rate of recurrence and rapid progression (2). The systemic inflammatory response is associated with the growth and progression of various cancer types (3-5). Recently, many studies reported that immunoinflammatory measures such as the neutrophil-to-lymphocyte ratio (NLR), platelet-to-lymphocyte ratio (PLR) and C-reactive protein (CRP)/albumin ratio (CAR), and inflammatory cytokines such as interleukin (IL)-6, IL10, and IL18, are related to survival outcomes in several malignancies (6-13). In EC, we previously reported that the CAR was the most significant predictor of overall survival (OS) among these immunoinflammatory measures in patients with EC and suggested a correlation between immunoinflammatory measures and inflammation in the tumor microenvironment (14). However, these immunoinflammatory measures are often affected by factors such as preoperative co-morbidities, the use of drugs, and noncancer-related as well as cancerrelated inflammation. For example, patients with EC with severe stenosis due to tumor may frequently have subclinical pneumonia and poor oral intake, leading to an elevated CRP level and hypoalbuminemia, respectively. Thus, we hypothesized that the combination of immunoinflammatory 
measures rather than a single measure more precisely predict the long-term outcomes in patients with EC.

In the present study, we established a novel inflammationbased prognostic score, the systemic inflammatory score (SIS), by combining existing immunoinflammatory measures and validated its prognostic value in patients with EC who underwent curative esophagectomy. In addition, we elucidated the relationship between immunoinflammatory measures and perioperative cytokine levels.

\section{Patients and Methods}

Patients. This study was performed with the approval of the Internal Review Board on ethical issues of National Defense Medical College, Tokorozawa, Japan (Approval number: 2967). A database containing 102 patients with primary EC who underwent radical esophagectomy between January 2009 and December 2014 at the National Defense Medical College Hospital was retrospectively reviewed. The tumor node metastasis criteria from the eighth edition of the Union for International Cancer Control classification system were used for tumor staging (15).

Evaluation of immunoinflammatory measures and definition. A peripheral blood test was performed before administering any treatments, including neoadjuvant chemotherapy. The NLR was defined as the absolute neutrophil count divided by the absolute lymphocyte count. The PLR was defined as the absolute platelet count divided by the absolute lymphocyte count. The CAR was defined by dividing the serum CRP level by the serum albumin level. Receiver operating characteristic (ROC) curves were censored for 5year survival to determine the optimal cutoff values of the indicators. The patients were categorized into high and low NLR, PLR, and CAR groups, respectively, as follows: NLR $>3.12$ and $\leq 3.12$; high PLR: $>230$ and $\leq 230$; and CAR: 0.085 and $\leq 0.085$. Each measure was scored 1 if it was above the cutoff value and scored 0 if it was the below that. The SIS was defined as the sum of these values. Figure 1 shows the calculation of the SIS and patients were divided into two groups: high SIS: $\mathrm{SIS}=2-3$ points, low $\mathrm{SIS}$ : $\mathrm{SIS}=0-1$ point.

Detection of serum cytokine levels. Blood samples drawn preoperatively and on the morning of postoperative day 1 were stored in tubes containing ethylenediaminetetra-acetic acid. For detection of serum ILs, samples were centrifuged at $1,000 \times g$ for $30 \mathrm{~min}$ at $4^{\circ} \mathrm{C}$ within $2 \mathrm{~h}$ after drawing. The plasma supernatants were carefully pipetted and transferred to polypropylene tubes and stored at $-80^{\circ} \mathrm{C}$ until analysis. Serum IL levels were measured with a commercially available enzyme-linked immunosorbent assay kit (Shino-Test Corporation, Tokyo, Japan) using a multifunctional auto analyzer (Bio-Rad 680; Bio-Rad laboratories, Tokyo, Japan) according to the manufacturer's instructions. The optical density of each sample was determined at an absorbance of $450 \mathrm{~nm}$ using a microplate reader (Well Reader SK-601; Seikagaku Corporation, Tokyo, Japan).

Statistical analysis. The statistical analyses were performed using the Wilcoxon test and chi-square tests. Hazard ratios with $95 \%$ confidence intervals $(95 \% \mathrm{CI})$ were used. We compared the discriminatory abilities of the factors to predict OS using the Kaplan-Meier method (log-rank test) and ROC curves to determine the area under the curve of these inflammation-based measures and

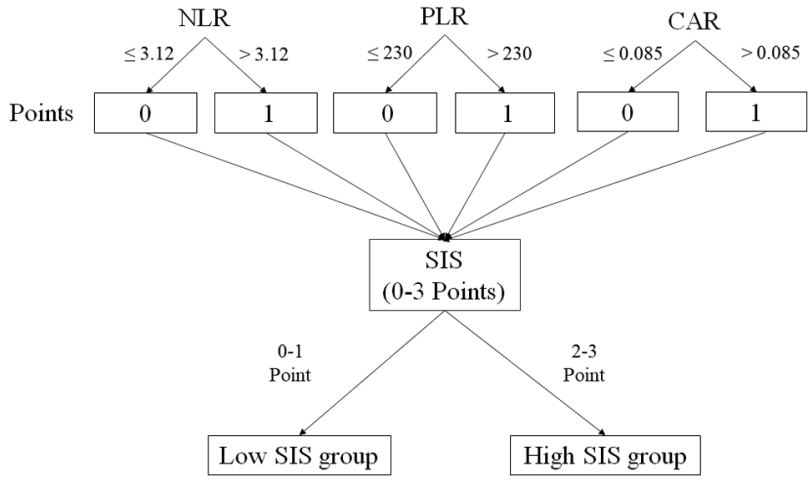

Figure 1. The method used for calculating the systemic inflammatory score (SIS). Each measure was scored 1 if it was above the cutoff neutrophil-to-lymphocyte ratio (NLR) of 3.12, platelet-to-lymphocyte ratio (PLR) of 230 and C-reactive protein/albumin ratio (CAR) of 0.085 , and scored 0 if it was below it. The SIS was defined as the sum of these values and patients were divided into two groups on the basis of SIS (high SIS: score 2-3; low SIS: score 0-1).

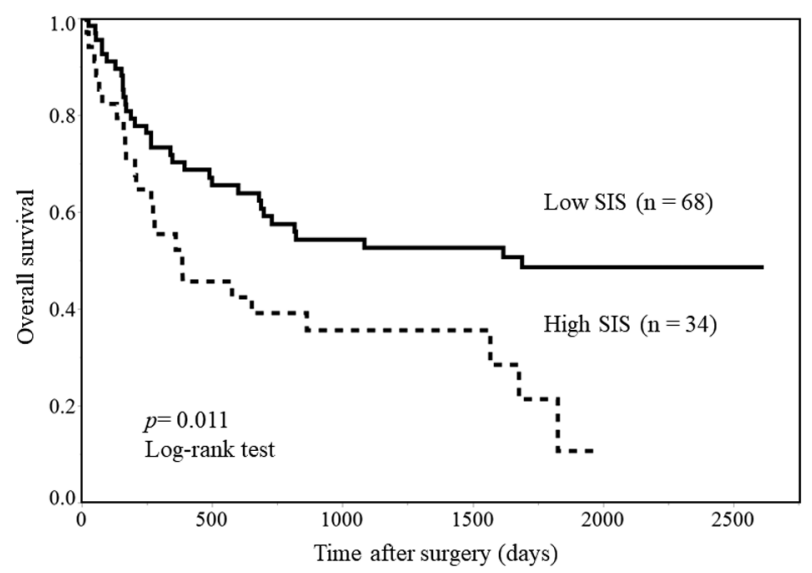

Figure 2. Overall survival curves for patients with esophageal cancer stratified by systemic inflammatory score (SIS). The high-SIS group displayed significantly lower overall survival rates than the low-SIS group $(p=0.011)$.

SIS. Univariate and multivariate analyses for OS were performed to examine the influence of clinicopathological features and the SIS.

All differences were considered significant at a value of $p<0.05$. All statistical analyses were performed using JMP 14 (SAS Institute Inc., Cary, NC, USA).

\section{Results}

Patient characteristics and relationships of SIS with clinicopathological features. The clinicopathological features are summarized in Table I. There were no 
Table I. Relation of systemic inflammatory score (SIS) with clinicopathological features.

\begin{tabular}{|c|c|c|c|c|c|}
\hline \multirow[b]{2}{*}{ Variable } & & Total & Low SIS (0-1) & High SIS (2-3) & \multirow[t]{2}{*}{$p$-Value } \\
\hline & & $\mathrm{n}=102(\%)$ & $\mathrm{n}=68(\%)$ & $\mathrm{n}=34(\%)$ & \\
\hline \multirow[t]{2}{*}{ Age } & $<75$ Years & $68(66.7)$ & $46(67.6)$ & $22(64.7)$ & \multirow[t]{2}{*}{0.766} \\
\hline & $\geq 75$ Years & $34(33.3)$ & $22(32.4)$ & $12(35.3)$ & \\
\hline \multirow[t]{2}{*}{ Gender } & Male & $88(86.3)$ & $56(82.4)$ & $32(94.1)$ & \multirow[t]{2}{*}{0.104} \\
\hline & Female & $14(13.7)$ & $12(17.6)$ & $2(5.9)$ & \\
\hline \multirow[t]{2}{*}{ Tumor location } & Upper & $15(14.7)$ & $13(19.1)$ & $2(5.9)$ & \multirow[t]{2}{*}{0.075} \\
\hline & Middle/lower & $87(85.3)$ & $55(80.9)$ & $32(94.1)$ & \\
\hline \multirow[t]{2}{*}{ Depth of tumor } & $\mathrm{T} 1$ & $27(26.5)$ & $24(35.3)$ & $3(8.8)$ & \multirow[t]{2}{*}{0.004} \\
\hline & $\mathrm{T} 2 / \mathrm{T} 3 / \mathrm{T} 4$ & $75(73.5)$ & $44(64.7)$ & $31(91.2)$ & \\
\hline \multirow[t]{2}{*}{ Lymph node metastasis } & No & $41(40.2)$ & $28(41.2)$ & $13(38.2)$ & \multirow[t]{2}{*}{0.775} \\
\hline & $\mathrm{N} 1 / \mathrm{N} 2 / \mathrm{N} 3$ & $61(59.8)$ & $40(58.8)$ & $21(61.8)$ & \\
\hline \multirow[t]{2}{*}{ Pathological stage } & $\mathrm{I} / \mathrm{II}$ & $45(44.1)$ & $32(47.1)$ & $13(38.2)$ & \multirow[t]{2}{*}{0.398} \\
\hline & III/IV & 57 (55.9) & 36 (52.9) & $21(61.8)$ & \\
\hline \multirow[t]{2}{*}{ Tumor type } & Squamous & $96(94.1)$ & $64(94.1)$ & $32(94.1)$ & \multirow[t]{2}{*}{$>0.99$} \\
\hline & Other & $6(5.9)$ & $4(5.9)$ & $2(5.9)$ & \\
\hline \multirow[t]{2}{*}{ Degree of differentiation } & Well & $12(11.8)$ & $9(13.2)$ & $3(8.8)$ & \multirow[t]{2}{*}{0.562} \\
\hline & Moderate/poor & $90(88.2)$ & $59(86.8)$ & $31(91.2)$ & \\
\hline \multirow[t]{2}{*}{ Operation procedure } & Open & $44(43.1)$ & $30(44.1)$ & $14(41.2)$ & \multirow[t]{2}{*}{0.777} \\
\hline & VATS & $58(56.9)$ & $38(55.9)$ & $20(58.8)$ & \\
\hline \multirow[t]{2}{*}{ Neoadjuvant chemotherapy } & Yes & $55(53.9)$ & $36(52.9)$ & $19(55.9)$ & \multirow[t]{2}{*}{0.779} \\
\hline & No & $47(46.1)$ & $32(47.1)$ & $15(44.1)$ & \\
\hline Neutrophil (/ml) & Mean \pm SE & $4172 \pm 202$ & $3485 \pm 161$ & $5546 \pm 429$ & $<0.001$ \\
\hline Lymphocytes (n/ml) & Mean \pm SE & $1563 \pm 56$ & $1729 \pm 68$ & $1232 \pm 72$ & $<0.001$ \\
\hline Platelets (n/ml) & Mean \pm SE & $244466 \pm 8119$ & $227485 \pm 8881$ & $278429 \pm 15249$ & 0.003 \\
\hline CRP (mg/dl) & Mean \pm SE & $1.235 \pm 0.203$ & $0.607 \pm 0.096$ & $2.491 \pm 0.520$ & $<0.001$ \\
\hline Albumin (g/dl) & Mean \pm SE & $3.846 \pm 0.058$ & $4.032 \pm 0.062$ & $3.474 \pm 0.094$ & $<0.001$ \\
\hline
\end{tabular}

CRP: C-Reactive protein; VATS: video-assisted thoracoscopic surgery. Statistically significant $p$-values are shown in bold.

differences in age, sex, tumor location, nodal involvement, pathological stage, tumor type, degree of differentiation, operative procedure, and frequency of receiving neoadjuvant chemotherapy between the two SIS groups, except for the tumor depth, which was greater in the group with a high SIS $(p=0.004)$.

Survival analysis associated with SIS. The OS rates were significantly worse in the high-SIS group than those in the low-SIS group $(p=0.011)$ (Figure 2$)$. The 5-year OS rates in the high and low-SIS groups were $10.7 \%$ and $48.7 \%$, respectively. The corresponding median survival time was 345 and 867 days, respectively. Univariate analysis demonstrated that age, tumor location, tumor depth, nodal involvement, and SIS were correlated with OS. Furthermore, multivariate analysis demonstrated that age $(\mathrm{HR}=2.10,95 \%$ $\mathrm{CI}=1.21-3.56, p=0.009)$, tumor location $(\mathrm{HR}=0.35,95 \%$ $\mathrm{CI}=0.20-0.62, p<0.001)$, tumor depth $(\mathrm{HR}=2.93,95 \%$ $\mathrm{CI}=1.30-5.09, p=0.008)$, nodal involvement tumor location $(\mathrm{HR}=1.99,95 \% \mathrm{CI}=1.07-3.93, p=0.030)$, and SIS $(\mathrm{HR}=1.96$, 95\% CI=1.11-3.41, $p=0.020)$ were independent prognostic factors for OS (Table II).
Comparison of prognostic values of NLR, PLR, CAR, and $S I S$. ROC curves were used to evaluate the discriminative power of these scores (Table III and Figure 3). The AUROC of SIS of 0.732 was the highest $(p=0.008)$, followed by those of CAR (0.712), NLR (0.618), and PLR (0.545).

Correlations between immunoinflammatory measures and perioperative cytokine levels. Table IV shows the relationship between immunoinflammatory measures and preoperative and postoperative serum IL6 and IL10 levels . The preoperative serum IL6 level in the high-SIS group was significantly lower than that in the low-SIS group (22.6 $\pm 8.0 v s .54 .2 \pm 10.3 \mathrm{pg} / \mathrm{ml}, p=0.046)$, although there were no differences in NLR, PLR, and CAR. There were no differences in the preoperative serum IL10 level by any immunoinflammatory measure. The postoperative serum IL10 level in the high-SIS group was significantly higher than that in the low-SIS group $(46.7 \pm 9.4$ vs. $30.0 \pm 3.6$ $\mathrm{pg} / \mathrm{ml}, p=0.047)$ but there were no differences in NLR, PLR, and CAR. In addition, there were no differences in postoperative serum IL6 level by any immunoinflammatory measure. 
in vivo $34: 3705-3711(2020)$

Table II. Prognostic factors for overall survival identified by univariate and multivariate analyses.

\begin{tabular}{|c|c|c|c|c|c|}
\hline \multirow[b]{2}{*}{ Parameter } & & \multicolumn{2}{|c|}{ Univariate } & \multicolumn{2}{|c|}{ Multivariate } \\
\hline & & HR $(95 \%$ CI $)$ & $p$-Value & HR $(95 \%$ CI $)$ & $p$-Value \\
\hline \multirow[t]{2}{*}{ Gender } & Female & 1 & 0.104 & & \\
\hline & Male & $2.00(0.88-5.75)$ & & & \\
\hline \multirow[t]{2}{*}{ Age } & $<75$ Years & 1 & 0.032 & 1 & 0.009 \\
\hline & $\geq 75$ Years & $1.82(1.06-3.07)$ & & $2.10(1.21-3.56)$ & \\
\hline \multirow[t]{2}{*}{ Tumor location } & $\mathrm{U}$ & 1 & 0.009 & 1 & $<0.001$ \\
\hline & $\mathrm{M} / \mathrm{L}$ & $0.49(0.28-0.84)$ & & $0.35(0.20-0.62)$ & \\
\hline \multirow[t]{2}{*}{ Depth of tumor } & $\mathrm{T} 1$ & 1 & $<0.001$ & 1 & 0.008 \\
\hline & $\mathrm{T} 2 / \mathrm{T} 3 / \mathrm{T} 4$ & $3.66(1.77-8.88)$ & & $2.93(1.30-5.09)$ & \\
\hline \multirow[t]{2}{*}{ Lymph node metastasis } & No & 1 & $<0.001$ & 1 & 0.030 \\
\hline & $\mathrm{N} 1 / \mathrm{N} 2 / \mathrm{N} 3$ & $2.60(1.46-4.94)$ & & $1.99(1.07-3.93)$ & \\
\hline \multirow[t]{2}{*}{ Degree of differentiation } & Well & 1 & 0.732 & & \\
\hline & Mod/Poor & $1.16(0.54-3.01)$ & & & \\
\hline \multirow[t]{2}{*}{ Operation procedure } & Open & 1 & 0.485 & & \\
\hline & VATS & $0.83(0.49-1.41)$ & & & \\
\hline \multirow[t]{2}{*}{ Neoadjuvant chemotherapy } & Yes & 1 & 0.201 & & \\
\hline & No & $1.41(0.83-2.42)$ & & & \\
\hline \multirow[t]{2}{*}{ SIS } & Low $(0,1)$ & 1 & 0.014 & 1 & 0.020 \\
\hline & $\operatorname{High}(2,3)$ & $2.00(1.15-3.41)$ & & $1.96(1.11-3.41)$ & \\
\hline
\end{tabular}

CI: Confidence interval; HR: hazard ratio; SIS: systemic inflammatory score; VATS: VATS: video-assisted thoracoscopic surgery. Statistically significant $p$-values are shown in bold.

\section{Discussion}

It is well known that cancer-related inflammation is associated with tumor proliferation and progression in various types of cancer (4, 5). Immunoinflammatory measures such as NLR, PLR, and CAR have been reported to predict long-term outcome in patients with EC (6-13). In this study, we showed that a high SIS was an independent prognostic factor for poor OS, and the AUROC for SIS was the highest among the measures investigated, suggesting that the SIS predicts the prognosis of patients with EC more accurately than the NLR, PLR, and CAR.

In this study, we demonstrated that patients with high SIS frequently had deeper tumor depth than those with low SIS, which was consistent with previous reports. Shimada et al. speculated that poor prognosis in patients with high NLR was associated with larger tumor volumes in gastric cancer (16). Tumor invasion is a neoplastic process that is strongly associated with cancer-related inflammation (4). However, the relationship between inflammation and tumor progression remains controversial. IL6 has been reported to play important roles in the inflammation of the tumor microenvironment and tumor progression via the signal transducer and activator of transcription 3 signaling pathway (17-21). Inflammation is generally considered to promote tumor invasion, and high serum IL6 has been associated with poor prognoses in different types of cancer $(22,23)$.
Table III. Area under the receiver operating characteristic curve (AUROC) for each immunoinflammatory measure.

\begin{tabular}{lcc}
\hline & AUROC & $95 \%$ CI \\
\hline NLR & 0.618 & $0.490-0.731$ \\
PLR & 0.545 & $0.420-0.665$ \\
CAR & 0.712 & $0.575-0.818$ \\
SIS & 0.732 & $0.617-0.823$ \\
\hline
\end{tabular}

CI: Confidence interval: NLR: neutrophil-to-lymphocyte ratio: PLR: platelet-to-lymphocyte ratio: CAR: C-reactive protein-to-albumin ratio: SIS: systemic inflammatory score.

However, some studies have suggested that proinflammatory cytokines (e.g. IL1 $\alpha$, IL1 $\beta$, IL6) derived from tumor specific CD4+ T-cells participate in cancer eradication by recruiting leucocytes from the systemic circulation, suggesting that nonspecific inflammation that lacks tumor specificity may even promote tumor development (24-26). In addition, some histopathological studies have shown that tumor infiltration by inflammatory cells may be associated with better prognoses in some types of cancer $(25,26)$. In this study, we demonstrated that the high-SIS group had lower preoperative serum IL6 levels than did the low-SIS group. Although we do not have a definitive answer regarding lower preoperative IL6 levels in the high-SIS group, these conflicting results might be the result of neoadjuvant chemotherapy or steroids 
A

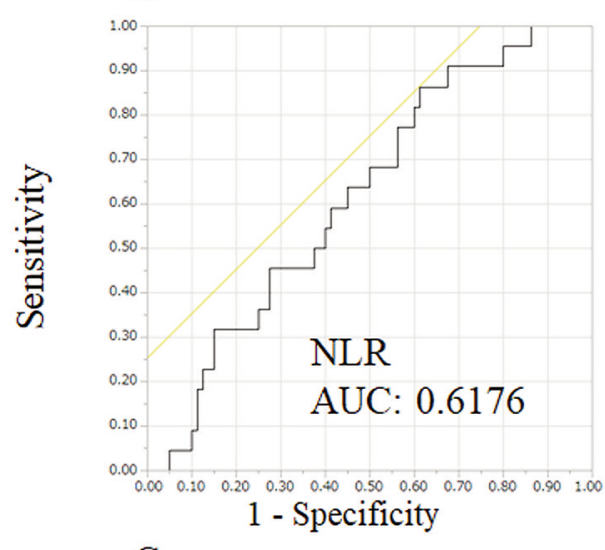

$\mathrm{C}$

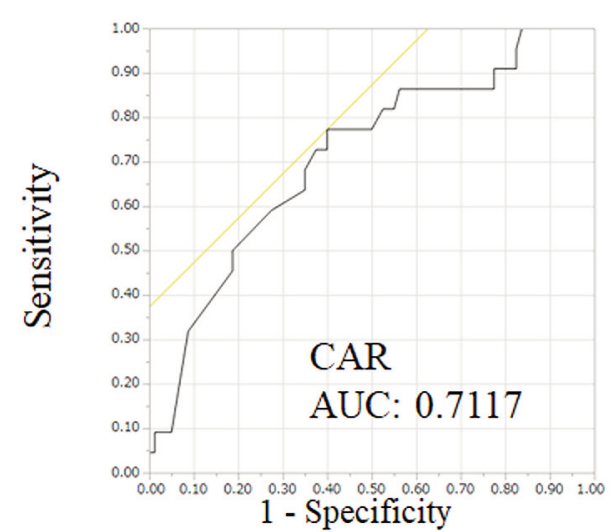

$\mathrm{B}$

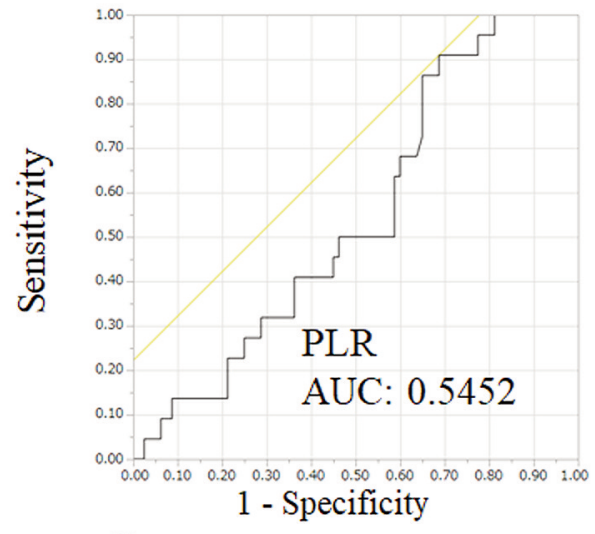

$\mathrm{D}$

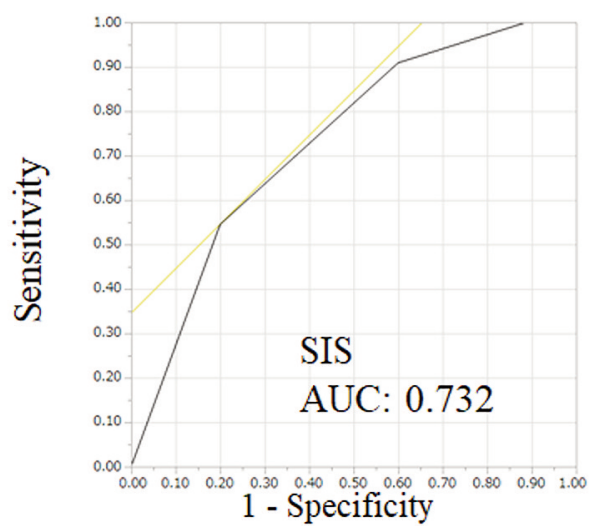

Figure 3. The receiver operating characteristic curves for the neutrophil-to-lymphocyte ratio $(N L R)(A)$, platelet-to-lymphocyte ratio (PLR) (B), Creactive protein/albumin ratio $(C A R)(C)$, and systemic inflammatory score $(S I S)(D)$. The area under the receiver operating characteristic curves (AUC) for SIS was the highest among measures investigated.

Table IV. The correlation between the systemic inflammatory score (SIS) and interleukin-6 and -10 levels.

\begin{tabular}{llcccc}
\hline & & Total & Low SIS $(0-1)$ & High SIS (2-3) & $p$-Value \\
\cline { 3 - 5 } Variable & & $\mathrm{n}=102$ & $\mathrm{n}=68$ & $\mathrm{n}=34$ & \\
\hline Interleukin-6 $(\mathrm{pg} / \mathrm{ml})$ & Pre & $43.62 \pm 7.49$ & $54.15 \pm 10.30$ & $22.56 \pm 7.99$ & $\mathbf{0 . 0 4 6}$ \\
& Post & $1,771.42 \pm 494.61$ & $2,283.50 \pm 730.22$ & $747.24 \pm 182.69$ & 0.144 \\
Interleukin-10 $(\mathrm{pg} / \mathrm{ml})$ & Pre & $11.82 \pm 1.78$ & $11.09 \pm 1.42$ & $13.29 \pm 4.55$ & 0.561 \\
& Post & $35.57 \pm 3.96$ & $30.00 \pm 3.55$ & $46.71 \pm 9.35$ & $\mathbf{0 . 0 4 7}$ \\
\hline
\end{tabular}

Pre: Preoperatively; Post: postoperatively. Data are means \pm standard error. Statistically significant $p$-values are shown in bold.

for premedication. In this study, the high-SIS group had significantly higher postoperative serum IL10 levels than the low-SIS group, but no difference was observed in the other immunoinflammatory measures. We speculated that a higher inflammatory state, characterized by a high SIS, is associated with a larger anti-inflammatory response after surgery.
Indeed, there is increasing evidence that higher expression of immunosuppressive factors in the serum and peritoneal cavity is associated with tumor progression and poor prognosis in patients with malignancies (27-29).

This study has some limitations. Firstly, it was conducted at a single institution using a retrospective design and a 
relatively small number of patients. Secondly, there are no universally agreed upon criteria for determining the cutoff values of NLR, PLR, and CAR for EC. A prospective study with more patients with EC is necessary to clearly establish appropriate cutoff values of NLR, PLR, and CAR.

In conclusion, SIS, which was calculated by combining existing immunoinflammatory measures, was found to be the most significant predictor of OS in patients with EC undergoing resection, and it may predict a higher postoperative IL10 level, which may be an indication of the higher inflammatory response and be associated with poor OS.

\section{Conflicts of Interest}

The Authors report no proprietary or commercial interest in any product mentioned or concept discussed in this article.

\section{Authors' Contributions}

Takafumi Suzuki, Yusuke Ishibashi, Hironori Tsujimoto, Shinsuke Nomura, Keita Kouzu, Yujiro Itazaki, Takao Sugihara, Manabu Harada, Nozomi Ito, and Hidekazu Sugasawa, contributed to the design and experiment of this study. Hironori Tsujimoto, Yoji Kishi, and Hideki Ueno contributed to writing the draft and supervising this study. All Authors have approved the article and agree with its submission.

\section{Acknowledgements}

The Authors would like to thank Enago (www. Enago.jp) for English language review.

\section{References}

1 Bray F, Ferlay J, Soerjomataram I, Siegel RL, Torre LA and Jemal A: Global cancer statistics 2018: GLOBOCAN estimates of incidence and mortality worldwide for 36 cancers in 185 countries. CA Cancer J Clin 68(6): 394-424, 2018. PMID: 30207593. DOI: $10.3322 /$ caac. 21492

2 Enzinger PC and Mayer RJ: Esophageal cancer. N Engl J Med 349(23): 2241-2252, 2003. PMID: 14657432. DOI: 10.1056/ NEJMra035010

3 Balkwill $\mathrm{F}$ and Mantovani A: Inflammation and cancer: Back to Virchow? Lancet 357(9255): 539-545, 2001. PMID: 11229684. DOI: 10.1016/S0140-6736(00)04046-0

4 Mantovani A, Allavena P, Sica A and Balkwill F: Cancer-related inflammation. Nature 454(7203): 436-444, 2008. PMID: 18650914. DOI: $10.1038 /$ nature07205

5 Mantovani A, Romero P, Palucka AK and Marincola FM: Tumour immunity: Effector response to tumour and role of the microenvironment. Lancet 371(9614): 771-783, 2008. PMID: 18275997. DOI: $10.1016 / \mathrm{S} 0140-6736(08) 60241-\mathrm{X}$

6 Zhao QT, Zhang XP, Zhang H and Duan DC: Prognostic role of platelet to lymphocyte ratio in esophageal cancer: A metaanalysis. Oncotarget 8(67): 112085-112093, 2017. PMID: 29340113. DOI: $10.18632 /$ oncotarget.22557

7 Zhang H, Guo XW, Yin XX, Liu YC and Ji SJ: Nomogramintegrated $\mathrm{C}$-reactive protein/albumin ratio predicts efficacy and prognosis in patients with thoracic esophageal squamous cell carcinoma receiving chemoradiotherapy. Cancer Manag Res 11: 9459-9468, 2019. PMID: 31819611. DOI: 10.2147/CMAR. S228113

8 Li S, Liu H, Diao C, Wang X, Gao M, Li Z, Song L, Gao X, Han J, Wang F, Li W and Han X: Prognosis of surgery combined with different adjuvant therapies in esophageal cancer treatment: A network meta-analysis. Oncotarget 8(22): 36339-36353, 2017. PMID: 28423740. DOI: $10.18632 /$ oncotarget.16193

9 Sato H, Tsubosa Y and Kawano T: Correlation between the pretherapeutic neutrophil to lymphocyte ratio and the pathologic response to neoadjuvant chemotherapy in patients with advanced esophageal cancer. World J Surg 36(3): 617-622, 2012. PMID: 22223293. DOI: $10.1007 / \mathrm{s} 00268-011-1411-1$

10 Ishibashi Y, Tsujimoto H, Yaguchi Y, Kishi Y and Ueno H: Prognostic significance of systemic inflammatory markers in esophageal cancer: Systematic review and meta-analysis. Ann Gastroenterol Surg 4(1): 56-63, 2020. PMID: 32021959. DOI: 10.1002/ags3.12294

11 Hirahara N, Tajima Y, Fujii Y, Yamamoto T, Hyakudomi R, Hirayama T, Taniura T, Ishitobi K, Kidani A and Kawabata Y: A novel prognostic scoring system using inflammatory response biomarkers for esophageal squamous cell carcinoma. World J Surg 42(1): 172-184, 2018. PMID: 28744596. DOI: 10.1007/s00268017-4144-y

12 Hyder J, Boggs DH, Hanna A, Suntharalingam M and Chuong MD: Changes in neutrophil-to-lymphocyte and platelet-tolymphocyte ratios during chemoradiation predict for survival and pathologic complete response in trimodality esophageal cancer patients. J Gastrointest Oncol 7(2): 189-195, 2016. PMID: 27034785. DOI: 10.3978/j.issn.2078-6891.2015.080

13 Chen LC, Li SH, Lo CM, Chen YH, Huang SC, Wang YM, Chou $\mathrm{SY}$ and Lu HI: Platelet-to-lymphocyte ratio is an independent prognosticator in patients with esophageal squamous cell carcinoma receiving esophagectomy. J Thorac Dis 11(11): 45834590, 2019. PMID: 31903247. DOI: 10.21037/jtd.2019.11.06

14 Ishibashi Y, Tsujimoto H, Hiraki S, Kumano I, Yaguchi Y, Horiguchi H, Nomura S, Ito N, Shinto E, Aosasa S, Yamamoto $\mathrm{J}$ and Ueno $\mathrm{H}$ : Prognostic value of preoperative systemic immunoinflammatory measures in patients with esophageal cancer. Ann Surg Oncol 25(11): 3288-3299, 2018. PMID: 30019304. DOI: 10.1245/s10434-018-6651-y

15 Brierley JD, Gospodarowicz MK and Wittekind C: TNM Classification of Malignant Tumours: Oxford, UK: WileyBlackwell 2017.

16 Shimada H, Takiguchi N, Kainuma O, Soda H, Ikeda A, Cho A, Miyazaki A, Gunji H, Yamamoto H and Nagata M: High preoperative neutrophil-lymphocyte ratio predicts poor survival in patients with gastric cancer. Gastric Cancer 13(3): 170-176, 2010. PMID: 20820986. DOI: 10.1007/s10120-0100554-3

17 Walter M, Liang S, Ghosh S, Hornsby PJ and Li R: Interleukin 6 secreted from adipose stromal cells promotes migration and invasion of breast cancer cells. Oncogene 28(30): 2745-2755, 2009. PMID: 19483720. DOI: 10.1038/onc.2009.130

18 Mano Y, Aishima S, Fujita N, Tanaka Y, Kubo Y, Motomura T, Taketomi A, Shirabe K, Maehara Y and Oda Y: Tumorassociated macrophage promotes tumor progression via STAT3 signaling in hepatocellular carcinoma. Pathobiology 80(3): 146154, 2013. PMID: 23364389. DOI: 10.1159/000346196 
19 Foran E, Garrity-Park MM, Mureau C, Newell J, Smyrk TC, Limburg PJ and Egan LJ: Upregulation of DNA methyltransferasemediated gene silencing, anchorage-independent growth, and migration of colon cancer cells by interleukin-6. Mol Cancer Res 8(4): 471-481, 2010. PMID: 20354000. DOI: 10.1158/15417786.MCR-09-0496

20 Segatto I, Berton S, Sonego M, Massarut S, Perin T, Piccoli E, Colombatti A, Vecchione A, Baldassarre G and Belletti B: Surgery-induced wound response promotes stem-like and tumorinitiating features of breast cancer cells, via STAT3 signaling. Oncotarget 5(15): 6267-6279, 2014. PMID: 25026286. DOI: 10.18632/oncotarget.2195

21 Chen MF, Chen PT, Kuan FC and Chen WC: The predictive value of pretreatment neutrophil-to-lymphocyte ratio in esophageal squamous cell carcinoma. Ann Surg Oncol 26(1): 190-199, 2019. PMID: 30362062. DOI: 10.1245/s10434-018-6944-1

22 Martín F, Santolaria F, Batista N, Milena A, Gonzalez-Reimers E, Brito MJ and Oramas J: Cytokine levels (IL-6 and IFNgamma), acute phase response and nutritional status as prognostic factors in lung cancer. Cytokine 11(1): 80-86, 1999. PMID: 10080883. DOI: 10.1006/cyto.1998.0398

23 Pelliniemi TT, Irjala K, Mattila K, Pulkki K, Rajamaki A, Tienhaara A, Laakso $\mathrm{M}$ and Lahtinen R: Immunoreactive interleukin- 6 and acute-phase proteins as prognostic factors in multiple myeloma. Finnish Leukemia Group. Blood 85(3): 765771, 1995. PMID: 7530507.

24 Haabeth OA, Lorvik KB, Hammarström C, Donaldson IM, Haraldsen G, Bogen B and Corthay A: Inflammation driven by tumour-specific Th1 cells protects against B-cell cancer. Nat Commun 2: 240, 2011. PMID: 21407206. DOI: 10.1038/ncomms 1239
25 Klintrup K, Mäkinen JM, Kauppila S, Vare PO, Melkko J, Tuominen H, Tuppurainen K, Makela J, Karttunen TJ and Makinen MJ: Inflammation and prognosis in colorectal cancer. Eur J Cancer 41(17): 2645-2654, 2005. PMID: 16239109. DOI: 10.1016/j.ejca.2005.07.017

26 Lee AH, Gillett CE, Ryder K, Fentiman IS, Miles DW and Millis RR: Different patterns of inflammation and prognosis in invasive carcinoma of the breast. Histopathology 48(6): 692-701, 2006. PMID: 16681685. DOI: 10.1111/j.1365-2559.2006.02410.x

27 Norian LA, Rodriguez PC, O'Mara LA, Zabaleta J, Ochoa AC, Cella M and Allen PM: Tumor-infiltrating regulatory dendritic cells inhibit CD8+ T cell function via $\mathrm{L}$-arginine metabolism. Cancer Res 69(7): 3086-3094, 2009. PMID: 19293186. DOI: 10.1158/0008-5472.CAN-08-2826

28 Gabrilovich DI, Chen HL, Girgis KR, Cunningham HT, Meny GM, Nadaf S, Kavanaugh D and Carbone DP: Production of vascular endothelial growth factor by human tumors inhibits the functional maturation of dendritic cells. Nat Med 2(10): 10961103, 1996. PMID: 8837607. DOI: 10.1038/nm1096-1096

29 Munn DH, Sharma MD, Lee JR, Jhaver KG, Johnson TS, Keskin DB, Marshall B, Chandler P, Antonia SJ, Burgess R, Slingluff CL Jr/ and Mellor AL: Potential regulatory function of human dendritic cells expressing indoleamine 2,3-dioxygenase. Science 297(5588): 1867-1870, 2002. PMID: 12228717. DOI: $10.1126 /$ science. 1073514

Received September 22, 2020

Revised October 5, 2020

Accepted October 6, 2020 